\section{Fan engagement in motorsports: A case of the FIA World Rally}

\section{Championships}

Hans Erik Næss, Sam Tickell

Social media success is increasingly being linked to profitable relations between sporting teams and their communities of fans. Through a case study of "RallytheWorld", Volkswagen's social media campaign 2013-2016 for the FIA World Rally Championship (WRC), this paper provides sports marketers with relevant practices on how to develop social media strategies and building relationships with and between the fans. Drawing upon theories of community facilitation and transmedia storytelling, as well as the method of autoethnography, our finding is that RallytheWorld, through its audience engagement techniques provided WRC fans with a new experience while respecting the championship's sporting traditions and non-competitive features. As a result, the case of RallytheWorld provides to sport marketers an innovative application of how a culturally informed utilization of transmedia storytelling is vital to develop social media strategies with the aim of building a relationship with and between the fans.
Keywords

social media, transmedia storytelling, motorsports, sport marketing, World Rally Championship

\section{INTRODUCTION}

Fan communities in sport can be defined as a "specialized, non-geographically bound community based on the relationships among consumers of a brand" (Yoshida, Gordon, Heere, \& James, 2015, p. 107). As positive fan engagement outcomes become clearer, many sports organizations have taken charge of promotion through social media channels like Facebook, Twitter and Instagram to craft narratives for the organization's strategic benefit and for the benefit of fan communities (Abeza, O'Reilly, \& Seguin, 2017; Content Factory, 2016; Meng, Stavros, \& Westberg, 2015). To achieve this benefit, we argue that merely using innovative technology is not sufficient. In order to create authentic relations between teams and fans, and between groups of fans, the promotional efforts must also be based on an understanding of the sport's cultural characteristics.

To advance this claim, this paper is an instrumental case study (Stake, 1995) of "RallytheWorld". This was the social media campaign of Volkswagen Motorsport, and formed an important part of Volkswagen's participation in the FIA World Rally Championship (WRC) 2013-2016. Since the WRC's inaugural year in 1973, it has grown from a niche sport far from mainstream media to a worldwide championship. In 2017, WRC reported a cumulative TV audience of 775 million; Eight million visitors interacted with WRC's social media (e.g., YouTube, Twitter, Facebook); there were more than 20.6 million sessions on wrc.com; and a total of 3.8 million people attended the 13 rallies of the 2016 season (WRC Fact book, 2017, p. 5).

The research question in this paper is how fan relations in the WRC were created and maintained by 
Volkswagen's social media campaigner Aperto and its use of transmedia storytelling as lead concept. In light of explorations of fan engagement and relationship marketing in sport (Abeza, O’Reilly \& Seguin, 2017; Sherwood, Nicholson \& Marjoribanks, 2017; Yoshida et al., 2015), this topic caught our attention for two reasons. First, Aperto, the marketing agency behind RallytheWorld, claimed that it would feature strategic use of "transmedia storytelling, compelling and involved from the very start" (Aperto, 2017). Although much is written about transmedia storytelling and sports in industry magazines, there are as far as we can tell few, if any, case studies of an actual campaign combining fan engagement and transmedia storytelling (see Stauff, 2018). Second, we privately began using RallytheWorld's offerings due to our interest in the championship and in relation to other research projects (Næss, 2014). As a result, this paper explores how social media campaigns in sports can be facilitated and implemented by coupling theories of transmedia storytelling and fan community engagement with an autoethnography of RallytheWorld.

\section{LITERATURE REVIEW}

According to Manoli (2018), sport marketing practice was originally designed to assist the commercial aims of teams and their partners. Gradually, a broader utilization of marketing tools and tactics took place as new media developed and the globalization of sports occurred. An important moment underlined by Manoli (2018, p. 1) is the 1983 book by Mullin. Here, Mullin argues that the most understudied, and potentially most valuable, fields of sport marketing are the psychological, sociological and cultural dimensions of fan interest. These dimensions became essential to exploit as sports and events grew to become brands, and as followers of sport diverged into a multitude of personalities which did not necessarily fit the usual fan typologies (Stewart, Smith, \& Nicholson, 2003). These followers developed new vertical (team-fan) and horizontal (fan-fan) ties (Yoshida et al, 2015), facilitated by new forms of interactive engagement (Collignon \& Sultan, 2014; Hutchins \& Rowe, 2012).

Against this backdrop, the development of RallytheWorld can be seen as a form of strategic sporting glocalization (Andrews \& Grainger, 2007, p. 488). It denotes the tailoring of goods and services on global basis to increasingly differentiated local markets (Robertson, 1995, p. 28). However, glocalization and its sporting expression symbolizes a process where media conglomerates have expanded as global businesses while their programs have increasingly catered to local markets. Numerous configurations are possible, and as depicted by Davis (2013):

audience fragmentation and channel and platform pro- liferation, along with ownership concentration in the media industry, invite strategies to create economies of scope by innovating 'convergent' media products-families of products with related content that are distributed in various versions and formats across platforms and channels (Davis, 2013, p. 176).

As addressed by Gronroos (2004), Williams and Chinn (2010), Abeza, O'Reilly and Reid (2013) and Abeza (2016), successful promotion of sport now requires relationship marketing rather than merely focusing on the transaction or social media as a dissemination tool. For example, referral marketing enables existing fans, third party influencers and other intermediaries to bring new followers to the sport (Bühler \& Nufer, 2010, p. 24). These findings open up for new research of sports with regards to people's escalating behavioural involvement in a fan community that includes "socially committed behaviors such as self-expression, story-telling, and fan community participation" (Yoshida et al., 2015, p. 108; see also Accenture, 2002; Chalip, 1992; Ferriter, 2009; Meng, Stavros \& Westberg, 2015).

This focus on fan community participation leads us to RallytheWorld and the campaign's theoretical foundation. As explained on Aperto's website, the company's strategy for merging the cultural history of the WRC with the social media world was to cre- 
ate an overarching narrative, based on the principles of transmedia storytelling. The concept was first explored in Henry Jenkins' Convergence Culture (2006), then with the Hollywood and gaming industries as lead examples, and can be defined as follows:

A transmedia story unfolds across multiple media platforms, with each new text making a distinctive and valuable contribution to the whole. In the ideal form of transmedia storytelling, each medium does what it does best - so that a story might be introduced in a film, expanded through television, novels, and comics; its world might be explored through game play or experienced as an amusement park attraction. Each franchise needs to be self-contained so you don't need to have seen the film to enjoy the game, and vice versa (Jenkins, 2006, pp. 95-96).

More specifically, this is organized through seven mechanisms, as summarized by Byun and Kwon (2016, p. 2): Spreadability vs. Drillability, Continuity vs. Multiplicity, Immersion vs. Extractability, World-building, Seriality, Subjectivity and Performance. We will come back to these specifics later as they 1) are central theoretical features of how transmedia storytelling works, and 2) provide ways to analyse the data from our exploration of RallytheWorld. It must be noted that in transmedia sto- rytelling the producer must acknowledge that "the show" is always smaller than the universe, which in turn includes large backstories and an ensemble of characters who are not always present in the context or geographic location (Jenkins, Ford, \& Green, 2013, p. 132). For example, if the user follows or interacts with just one or two communication channels in a scenario where there are five, that person needs to get enough information about the sport to know what is going on. However, if that person engages with all channels, she gets a complimentary experience of the sport where "the whole is greater than the sum of its parts" (Phillips, 2012, p. xi).

Although Jenkins' concept was received with interest from media industries and researchers, it also received criticism on three areas. First, the idea that storytelling had to be a part of every communication channel available on a market implied a large implementation plan where detours could lead people astray. For example, the TV series Lost, which used transmedia storytelling as dramaturgical backbone, ended up pursuing the conceptual technicalities of fan exploration and series extension instead of developing the characters and unfolding the plot (Mittell, 2015, p. 306). Second, as argued by Scolari and Ilbrus (2014, p. 2193), "it is necessary to become explicitly concerned about all the manifestations of social power that have conditioned the emergence of transmedia practices and about the new forms of dominance that these practices may have enabled." Among WRC fans, this power element is not necessarily immediately relevant. It should be noted that a hegemonic interpretation of the championship's development does matter to many fans, as it provides them a source of comparison with the current status of the WRC. Consequently, fans are not indifferent to what parts of the sport's identity that are emphasized (O'Connor, 2005; Næss, 2014). Third, an over-utilization of the concept could cloud the message and thus be counterproductive as "fan attraction mechanism" (Pronschinskse, Groza, \& Walker, 2012, p. 221), or as outlined by Sangalang, Johnson and Cianco (2013):

To fully understand the benefits and limitations of transmedia storytelling, a theoretical framework must be able to account for the influence of individual narratives that appear in singular media platforms and the influence of cumulative exposure to narratives across media (pp. 130-31).

If the story is too differentiated and require too much effort, only diehard fans will engage sufficiently to reap the rewards, which was not Aperto and VW's aims. We argue that Aperto resolved this challenge by utilizing "bridging functions" of social media its scheduling and coordination of social interaction 
(Sanderson \& Kassing, 2014) - to facilitate a circumsocial community.

This concept of circumsocial community is derived from the concept of parasocial interaction, first suggested by Horton and Wohl (1956). In the context of sports, parasocial interaction means that with the invention of mass media the sport audiences would engage in new forms of social interactions with athletes and teams. These interactions are termed parasocial as people approached athletes or celebrities as they would encounter them in a typical social/interpersonal relationship (Boehmer, 2016, p. 466), although no two-way communication took place. This kind of relationship, which in some cases has led to increased fandom, has been documented in other motorsport studies of e.g. NASCAR (Spinda, Earnheardt, \& Hugenberg, 2009) and Formula 1 (Hartmann, Stuke, \& Daschmann, 2008). Although there is an increase in social interactions between athletes and fans it is "not yet the norm" (Boehmer 2016, p. 466). Instead, a new form of interaction has emerged, coined circumsocial, as a way to describe "how new media facilitate orbital or spherical patterns of fanathlete interaction-moving between and capitalizing on relational attributes that are more or less parasocial/social in nature" (Kassing \& Sanderson,
2015, p. 12). To demonstrate how RallytheWorld can be seen as a case of circumsociality, we now introduce the case and the methods used.

\section{CASE AND METHODS}

We understand the case study research method "as an empirical inquiry that investigates a contemporary phenomenon within its real-life context; when the boundaries between phenomenon and context are not clearly evident; and in which multiple sources of evidence are used" (Yin, 1994, p. 23). Against this backdrop, we treat VW's social media campaign RallytheWorld as an instrumental case study (Stake, 1995). Rather than viewing the case study as intrinsic (focusing on a unique case) or collective (where several cases are gathered) (Stake, 1995, p. 16), the choice of RallytheWorld as an instrumental case refers to a recurring or "dominant" (Stake, 1995, p. 16) issue in sport communication: how to engage fans through social media?

\section{Case selection}

Our choice of RallytheWorld as case for exploring this topic instead of the WRC's official campaign was first motivated by differences in consumer orientation. In contrast to the official WRC social media program headed by WRC Promoter GmbH, which was quite conventional, RallytheWorld was composed of interactive modules parsing out content and instigating interaction on a number of communication arenas. Although Volkswagen Motorsport's centralised area for engaging with the fans was rallytheworld.com, which provided access to everything else related to the campaign, there were numerous other platforms for fan-team or fan-to-fan interaction. Second, VW's media strategy differed from the other WRC teams. Rather than using parent company accounts on social media as promotional arenas for WRC activities, RallytheWorld utilized Facebook, Twitter, and YouTube, as well as its own web page, initiatives separate from Volkswagen AG or even Volkswagen Motorsport. Third, we noticed that it had become a talking point among people in the world of rallying. The reason was it enabled participatory consumption of the sport in a different way than social campaigns from other WRC teams. WRC Radio presenter Becs Williams summarized it like this in 2017:

I have worked in the WRC for 15 years and followed the sport before that. I have never seen any other team bring the rally to the people like Volkswagen did. All the work they were doing through the RallytheWorld website, people all over the world, no 
matter what language they spoke, felt close to the rally (Absolute Rally Podcast, 2017).

These discoveries were then seen as confirmation that RallytheWorld satisfied the uniqueness criteria in order to be considered as an instrumental case warranting further investigation (Harrison, Birks, Franklin, \& Mills, 2017).

Methods

Due to our own increasing engagement in the WRC we found that one relevant method for this case was autoethnography. According to Ellis, Adams and Bochner (2011) this is a method designed to "describe and systematically analyze personal experience in order to understand cultural experience". It enables researchers to "retrospectively and selectively write about epiphanies that stem from, or are made possible by, being part of a culture and/or by possessing a particular cultural identity" (Ellis, Adams, \& Bochner, 2011). Some forms of autoethnography did not suit our investigation. Instead of the interpretivehumanistic, critical, or creative-artistic autoethnography we preferred the social-scientific version of autoethnography. What differentiates the latter, according to Manning and Adams (2015), is that in the context of popular culture - in which the WRC can be placed - this form of autoethnography "involves a combination of fieldwork, interpretive qualitative data, systematic data analysis, and personal experience to describe the experiences of being in, or a part of, a community" (p. 191).

Our social-scientific autoethnographic explorations of RallytheWorld meant that we participated in the campaign as users of the activities made available by the campaign. Instead of being active community members as in posting images on Instagram and uploading content on other social media platforms, we participated as "professional lurkers" (Kozinets, 2002, p. 68; see also Quinton \& Harridge-March, 2010) with the intention of anonymously becoming a part of the community and observing the development of user-team activities related to RallytheWorld. In this process, we gathered data that resembles what Gray (2010, quoted in Tussey, 2013, p. 41) categorized as promotional paratexts. These paratexts, a concept which derives from the work of Genette (1997), includes "short video clips, audience opinion polls and contests designed to contextualize audience understanding of television content" (Tussey, 2013, p. 41). Additionally, they can involve any "ancillary content that surrounds primary media texts" (Oates \& Vogan, 2014, p. 328). These paratexts were therefore collected besides watching the official WRC programmes aired by the championship promoter's partnering broadcasters.
In practice, inspired by the close relationship between the principles of transmedia storytelling and the function of paratexts in digital media (Desrochers \& Apollon, 2014), we scouted four sources - rallytheworld.com, Instagram, Twitter, and Facebook - for narrative examples that were paratexts and transmedia storytelling snippets at the same time. Data collection was conducted prior to, during, and after the 12 four-day WRC events in one season, and lasted from January 2013 to December 2016, when Volkswagen pulled out of the WRC and took down rallytheworld.com. As we searched for paratexts that could match the principles of transmedia storytelling, relevant examples came unpredictably in batches instead of being evenly distributed across the years. After gathering about 65-70 paratexts from various platforms and situations of each transmedia storytelling principle, and nearing the end of 2016 when it still was not official that Volkswagen would withdraw from the WRC, we made a selection of five-to-six examples as we sensed a saturation in the data where the new that was discovered would not add significant data or add to the overall story RallytheWorld was telling (Strauss \& Corbin, 1990, p.136)

This selection process was systematized in accordance with the principles of transmedia storytelling in two ways. First, prior research on the cultural sources of fan-engagement in the WRC (Næss, 2014; 
2016) gave us some direction in terms of deciding whether various features of the RallytheWorld campaign represented more than "add-ons, spinoffs, and also-rans", and therefore were responsible for "many of the meanings that we associate with them" (Gray, 2010, p. 6). Second, in connection with the first, we investigated to what extent the paratexts could demonstrate that RallytheWorld simultaneously renewed the communication of the sport's non-competitive features while appreciating those sources. Both processes were characterized by what Creswell (1998) called "direct interpretation". This means that "the case study researcher looks at a single instance and draws meaning from it without looking for multiple instances" (Creswell, 1998, p. 154). As consumers of RallytheWorld offerings we also agree with Merriam's (1998) claim that "[t]he interest is in process rather than outcomes, in context rather than a specific variable, in discovery rather than confirmation" (p. 19). For that reason, we argue that the value of this instrumental case study does not depend on being able to defend the typicality of the case (Stake, 1995, p. 4). Instead, it is appropriate for developing theories and induce new research that facilitate understanding of issues identified (Feagin et al., 1991; Stake, 1995).

FINDINGS

In the context of the glocalization of sport and so- cial media campaigns, RallytheWorld is an example that a campaign's unifying logic is as central to the analysis as the separate expressions of it. To specify the analytical links between transmedia storytelling, paratexts, and the emergence of a circumsocial community of WRC fans, we now turn to the first feature of transmedia storytelling: spreadability/drillability. The former element underlines the importance of exploiting specific digital platforms for expanding the narrative and its parts, whereas the latter element refers to the level of penetration into the targeted audience. The second principle is continuity/multiplicity, where the former refers to how the narrative is continued across various media, and the latter refers to alternative takes on the story (for instance through fan fiction, or, in the case of the WRC, competing online with the official WRC video game). To operationalize these first four elements of transmedia storytelling Aperto created a digital hub, rallytheworld.com, which

provides the global fan base with access to the circuits, challenges, and team pilots. A social media buzz, mobile gaming, live events and competitions ensure the fans get a piece of the action - and keep coming back for more for over twelve months. These fan events are equally spectacular as the championship itself: whether the search for a helmet holder, voting for the perfect fan food, or being one of the 4,00o faces on the Fan Car as a photo stuck to the Polo R WRC (Aperto, 2017).

An integral part of this hub was a seamless multimedia experience (regardless of technological platform), which offered, us as users, unique material for each new WRC event. Throughout the 2015 season, for example, we could access tailored video content for each of the rallies with location and culturally appropriate references and spoofs being made. The Finnish WRC event's video featured a sauna; Argentina - a barbeque (asado); Italy - espresso. Such personalization of content was not selected merely as paratexts based on autoethnographic impressions. According to Gruszka (2015) these videos resonated with a broader community of fans: "Those commercials promote both the brand and the country. The creators did something good not only for themselves and that's why we instantly like them."

Gruszka's comment about "brand and country" brings us to the third principle of transmedia storytelling: immersion/extractability. Driven by the aim of immersing users in the world it creates and to bring it into real life, this principle was realized through the combination of online and onsite offerings related to RallytheWorld. It was present at nine WRC events in 2014 with the aim of digitalizing live rally experiences. This was possible through a stand at the WRC service 
park, a multiplex area where the cars are serviced between the speed tests, food and drinks are on sale, as well as competitions, merchandise, attractions to create a motoring theme park. Among the innovations were the 4D motion "virtual donut". There we could enter a greenbox, whose keying technology has been specifically developed for VW's setup, and take part in film in real-time where world champion Sébastien Ogier spins his Polo R WRC around us, an experience that according to Köhler (2014) became popular to share online. Another example was the opportunity at the service park to play the officially licensed WRC game by driving the Polo in an arcade machine.

This relational approach to fans links to the fourth principle of transmedia storytelling: World-building, or how the narrative intersects with the users' daily life and, we would argue, socializing into the sport. Although Aperto wanted to grasp fans outside the core base of WRC, it also needed to utilize the championship's history in order to make it a coherent narrative. As an example, to explain why some WRC rallies or some locations at each WRC event are wellknown to existing fans, it was necessary to include a historical contextualization (or world-building). One example, which easily could be shared with other fans as it used YouTube as platform, was our opportunity to watch VW driver Andreas Mikkelsen make the famous "Colin's Crest” jump at Rally Sweden 2015.
We were given a bird's eye view of the scene and then seven pointers (which led to different angles) on the screen which we could choose from. In other circumstances, this contextualization of an event was done with a humorous twist as explained through Aperto's nomination for the Shorty Awards (an international annual awards show honouring the best of social media).

Creating different scenarios inspired the country, history and challenges of each rally. During Rally Sweden we took the universal frustration of IKEA's self-assembly furniture into the Volkswagen garage. Creating a sketch where a mechanic receives the infamous IKEA manual to assemble the Polo WRC R. We see the thousands parts he must put together, before cutting to the single, tiny Allen-key they've supplied to do the job (Shorty Awards 2017).

On Facebook, Twitter, YouTube and Instagram, fans helped create this historical contextualization by utilizing the existing narrative and reframing it with the use of social media tools. On Twitter, fans could upload their own images at \#rallytheworld to contribute in documenting the action during a WRC event. Prior to Rally Sweden 2017, one fan posted an image where he explained how to behave as a spectator during the rally ("How to stay warm at a rally") by referring to the cold winter and the sometimes-ridiculous spectating habits of Scandinavian rally fans. This culturalisation of the rally experience seeks to maintain audience interest in the WRC and to create an expectation of interesting content for each event - adding to the media outcomes for each WRC event. This relates to Jenkins fourth principle for transmedia storytelling, which allows the user to explore the insight into the characters and their motivations (Jenkins, 2007). As an example, we could post questions on Twitter to VW driver Jari-Matti Latvala during Rally Argentina 2016 (\#askJML). Many questions were connected to the special atmosphere of this event, which were answered in a YouTube interview.

The fifth principle Jenkins outlines is seriality. Rather than sequential, this kind of seriality is hypertextual, delivering the story across multiple media outlets in chunks adapted to the specific platform. An example of this principle was the 2016 competition on RallytheWorld where six fans were selected to undergo a "rally boot camp" with the Volkswagen Driving Experience. One of the team drivers then took them over "Colin's Crest" at full speed in a VW Polo R WRC. Another example was the information service launched by VW at Rally Germany in 2016, where we, through signing up with our smartphones, could combine three distribution lists as we wished. Volkswagen offered a choice between the lists "Essen- 
tial", "Emotional" and "Additional" in WhatsApp, Instagram and Telegram. As such, every user could configure their own personal information service, and could modify it at any time. Finally, we could contact the Volkswagen Motorsport team directly via the individual chat function. Unlike on social networks like Twitter and Facebook, these chats took place privately rather than in public. In our experience, this prompts greater involvement from the user as it allows for more personal communication than a shared discussion while still progressing the narrative within the context the local event and global championship.

Jenkins sixth principle is subjectivity, that is, the contemporary presence of different point of views of the same narrative universe. To achieve this, RallytheWorld portrayed various sides of WRC life and poked fun at its team. Again, the nomination for the Shorty Awards describes it well as it links our search for paratexts with transmedia storytelling.

Polo WRC R. When the container doors opens up in Portugal, Latavala (sic) appears like a bear from hibernation. The usually clean-shaven driver, almost unrecognisable with long beard - the ultimate dedication. Wherever possible, we used the real mechanics over trained actors, a decision which favoured quick, physical comedy over lengthy dialogue (Shorty Awards 2017).
Lastly, the seventh principle of transmedia storytelling is performance, which refers to the protagonism openly given to the users in contributing to the development of the narrative world. To operationalize this principle, Aperto created the Social Fuel Initiative. This incentivised social media usage through connecting the team with their fellow fans and the fans with each other. The reward-based initiative gave one point when we clicked on an article on RallytheWorld. com, two points for watching a video, and five points for sharing content from RallytheWorld on Facebook. Eventually people could win prizes. Every click, view, like or share was rewarded with more "social fuel". A fuel gauge on rallytheworld.com showed the status of this virtual fuel. The fuller the tank, the more benefits were unlocked, such as new videos of the RallytheWorld mockumentary, various surfaces for the $3 \mathrm{D}$ drift, the rally game "RallytheWorld" and other interactive content.

\section{DISCUSSION}

So how did these seven features help enable circumsocial interaction? Aperto used transmedia storytelling to construct a symbolic community, which mirrors Cohen's (1985, p. 12) understanding of the concept in two ways: that the members of the group a) have something in common with each other, which b) distinguishes them in a significant way from the members of other putative groups (such as Formula 1 fans). The combination of these criteria implies a boundary-making process that is defined in relation to others:

The quintessential referent of community is that its members make, or believe they make, a similar sense of things either generally or with respect to specific and significant interests, and, further, that they think that that sense may differ from one made elsewhere. The reality of community in people's experience thus inheres in their attachment or commitment to a common body of symbols (Cohen, 1985, p. 16).

This creation of a common "body of symbols" among WRC fans was possible due to what Kassing and Sanderson (2015, p. 4) name "bonding agents that signal community membership" and historical insights. To meet VW's requirement of reaching other fans than the motorsport devotees, Aperto chose a different approach than the official WRC apparatus, which, judging by the WRC Fact book (2017), relied more on consumer statistics and demographics to pen its social media strategy. In 2016, 97\% were male and 55\% were between 25-44 years of age (WRC Fact book, 2017, p. 27; see also Hassan \& O'Connor, 2009).

However, many WRC fans can engage with the sport as nationality, age, gender, religion, or class 
are irrelevant to community access (Næss, 2014; see also Absolute Rally Podcast, 2017; Gruszka, 2015; Rasku \& Ahonen, 2015). In our visew, Aperto circumvented these sociological categories by enabling the participants to become narratively proficient. RallyTheWorld provided the possibility to use knowledge about the championship's past and present; and the generative relation between various regulatory eras, drivers, teams, and cars in the sport; as well as exploring the cultural and technological possibilities of being a rally spectator; and to engage with others in the WRC community. As a result, our and others' entry to this circumsocial community was not guarded by traditional demographics or inclusion criteria set beforehand, or even along the way, but aided by common technology to access the basic stories and culture of the WRC.

Assuming that the official promoter handled conventional sports programming, Aperto could concentrate on social media opportunities for reaching new fans and, ultimately, creating new VW rally team followers through bonding agents such as the Social Fuel Initiative and RallytheWorld main hub. Said differently, Aperto expanded the market by particularizing the product. What we call "everyday fans", or those who see their interest in the sport as a hobby and not as a way of life (Busse \& Gray, 2011), was seen by Aperto as equally important as potential consumers of RallytheWorld products as the motorsport devotees. As Aperto (2017) said, "The task: seeing and experiencing the rally from Volkswagen's perspective. Not only for the fans on the sidelines, but for everyone". This was an essential decision by Aperto as "a key challenge in transmedia product design" (Davis, 2013, p. 184) is to avoid over-utilization of the theoretical apparatus, as discussed above, and instead find ways "to accommodate natural variation in the degree of audience engagement throughout the extended property" (Davis, 2013, p. 184).

It is not certain that Aperto grasped the full extent of the elements of transmedia storytelling. While we do not accuse Aperto of cherry-picking, as it clearly made use of the seven characteristics of transmedia storytelling, the company did not necessarily explore all the little things associated with each of these seven characteristics. Space does not allow us to pursue this argument further, but, as elaborated by Jenkins (2006; 2013), there are additional mechanisms for engaging the audience compared to RallytheWorld. In addition, RallytheWorld is not fiction - there is no single "plot" but a series of "stories" drawn together through the unique circumstances of the WRC. Despite this, and the symbolic specifics of this particular motorsport community, we argue that our findings and this case are relevant to other sports as the findings can be adapted to their unique situation in terms of relationship marketing. Although the challenge of coping with "the constantly evolving SM technology as well as repurposing emerging platforms" (Abeza, O'Reilly, \& Seguin, 2017, p. 17) has been highlighted as crucial for sport marketers, the discovery of a community makes us argue that providing engaging content matter more than the platform on which it is offered (see also Jenkins, Ford, \& Green, 2013). For instance, by creating unique movies for each rally along with games and other enhanced media, Aperto created a mode of belonging where we could integrate rally media into our daily lives, finding information, insight and identity in that media that resonated with our way into fandom. Let us illustrate this with a final example from RallytheWorld:

At Rally Finland, we used their most famous export - an old-school Nokia phone. We see a fan playing the nostalgic game of 'Snake'. However, the snake is replaced by an 8-bit Polo. As it makes its way around the phone screen it appears to exit the phone. With perfect timing and alignment a real Polo WRC R zooms past, taking on its path and totally surprising fans. Using live footage mean for short windows of time to create, cut and edit together footage while the rally was ongoing (Shorty Awards 2017).

For those of us who grew up with Snake at the same 
time as we got engaged in the WRC, and in addition experienced the smartphone revolution when in our twenties, this hybrid usage of technologies, together with the Social Fuel initiative, worked well as a primitive, yet effective example of "gamification". By applying game features in a non-game context (Kunkel, Funk, \& Mueck, 2014), Snake provided something additional to the live rally experience. By combining what Kassing and Sanderson (2015) called "social levelling practices", "invitational uses" and "bridging functions", that together confirm membership in the community, this game built upon the WRC's important marketing affiliations. As outlined by O'Connor (2005), this included both licensed (the official WRC game) and non-licensed simulator games (such as the Colin McRae game series) on PlayStation and Xbox that we had been playing since the late 1990s. Consequently, in a general sense, it further socialized the sport and added greater context to the fan-aware challenges that the rally drivers face during competition while being light enough to try to encourage a new fan to interact with the content. It also bridges the gap that inevitably occurs between rallies where there may not be information in a traditional news sense to provide to the fans. That way, Aperto made it possible to combine the four key strategies in the production of branded content: entertainment, information, education, and function (Kunz, Elsässer, \&
Santomier, 2016, p. 523).

\section{CONCLUSION}

There are plenty of sport business reports highlighting the relevance of linking transmedia storytelling with brand awareness strategies through social media. At the same time, the implementation of this combination in actual marketing strategies is somewhat neglected as research area (exceptions include Ford, 2017; Kunz, Elsässer \& Santomier, 2016; McClearen, 2017). Our analysis of RallytheWorld has tried to fill this void by exploring how Aperto created fan engagement in a motorsport community through the means of social media and transmedia storytelling. Like many other social media agencies Aperto took advantage of "prosumers". Originally coined in the 1980 , it has in the context of social media been reinvented to describe networked individuals who simultaneously can produce, distribute and consume their own goods or services (Santomier \& Hogan, 2013, p. 179; see also Hutchins \& Rowe, 2012; Pegoraro, 2014; Rowe, 2011).

However, what makes the RallytheWorld campaign an instrumental case, and a learning example for the industry on how to craft a social media strategy in sports, is the way it enabled its strategy of transmedia storytelling to facilitate a bond of belonging to the WRC as a whole between its community members. Before the campaign started, there was no lack of warnings from the marketing industry that new communication technology in itself could not reinvent consumer relations (Feloni, 2013). Aperto's response was to implement a creative view on the relation between the sport's past and present - with notable emphasis on non-competitive elements - as the basis for interactive endeavours on social media. By blending user-generated content with professionally edited paratexts, Aperto and RallytheWorld could take full advantage of the diversity of Jenkins' theoretical concept and expand the notion of "a WRC fan". Similar to the study of fan engagement on Facebook by Pronschinske, Groza and Walker (2012), who found that "page attributes signaling authenticity and user engagement have the greatest impact on attracting and maintaining a Facebook fan base" (p. 221), we argue that Aperto's success relied on perceptions of the WRC's sporting authenticity to enhance fan relations beyond the VW team.

At the same time, we acknowledge the limitations of this study. Despite the glocal significance of RallytheWorld as a media campaign, it is only one of many possible cases in sports, where some may contrast our findings. The relationship between the global and the local is always conditioned by cultural characteristics that go far beyond the technologies of social media in complexity. Issues for further research include 
whether this complexity is a burden or an opportunity, and how other cases have coped with the challenge to strike a balance between global reach and local engagement. Examples could include professional road cycling, sailing, or other sports where the primary contest is not between nations but between teams of various composures. Moreover, it would be fruitful to adapt other qualitative methods to these studies as there is an suntapped study potential in different generations of sport consumers, for example how the experience of the radical changes in sport, media, and technology affect people's engagement for sports in general. Finally, further case studies like the one presented here could be useful in developing sport marketing models such as the one developed by Williams and Chinn (2010).

\section{Hans Erik Næss}

Associate professor, Kristiania University College

HansErik.Naess@kristiania.no

\section{Sam Tickell}

Ghent University

Samuel.Tickell@UGent.be

\section{REFERENCES}

Abeza, G. (2016). Social Media in Relationship Marketing: The Professional Sport Context. PhD thesis, School of Human Kinetics, University of Ottawa.

Abeza, G., O'Reilly, N., \& Seguin, B. (2017). Social Media in Relationship Marketing: The Perspective of Professional Sport Managers in the MLB, NBA, NFL, and NHL. Communication \& Sport, 7(1), 80-109. DOI: https://doi.org/10.1177/2167479517740343

Abeza, G., O’Reilly, N., \& Reid, I. (2013). Relationship Marketing and Social Media in Sport. International Journal of Sport Communication, 6(2), 120-142. doi: 10.1123/ijsc.6.2.120

Absolute Rally Podcast (2017). Episode 8, Season 6. N.p. Retrieved from https://totalrallystudio.podbean.com/. Accessed 17 June 2017.

Accenture (2002). World Rally Championship: Driving High Performance in New Media Technologies. Accenture: London. Retrieved from http://www.accenture. com/SiteCollectionDocuments/PDF/wrc_blockbuster. pdf. (accessed 19 August 2011).

Andrews, D. \& Grainger, A. (2007). Sport and Globalization. In G. Ritzer (Ed.) The Blackwell Companion to Globalization (pp. 478-498). Oxford: Blackwell.

Aperto (2017). RallytheWorld. Retrieved from: http:// www.aperto.com/en/work/volkswagen-wrc (accessed 22 May 2017).
Boehmer, J. (2016). Does the Game Really Change? How Students Consume Mediated Sports in the Age of Social Media. Communication \& Sport, 4(4), 460-483. https://doi.org/10.1177/2167479515595500

Busse, K. \& Gray, J. (2011). Fan Cultures and Fan Communities. In V. Nightingale (Ed.), The Handbook of Media Audiences (pp. 427-442). Chichester, U.K.: Wiley-Blackwell.

Bühler, A. \& Nufer, G. (2010). Relationship Marketing in Sports. London: Routledge.

Byun H., \& Kwon, Y.S. (2016). A Systematization of the Concept of Transmedia: Update, Reinterpretation and Redefinition of the Concept. International Journal of Journalism \& Mass Communication, 120, doi: http:// dx.doi.org/10.15344/2349-2635/2016/120

Chalip, L. (1992). The Construction and Use of Polysemic Structures: Olympic Lessons for Sport Marketing, Journal of Sport Management, 6, 87-98.

Cohen, A. P. (1985). The Symbolic Construction of Community. London: Tavistock.

Collignon, H., \& Sultan, N. (2014). Winning in the Business of Sports. An AT Kearney report. Paris and Doha. Retrieved from: https://www.atkearney.com/ documents/10192/5258876/Winning+in+the+Bu siness+of+Sports.pdf/ed85b644-7633-469d-8f7a99e4a5oaadc8 (accessed 11 October 2016). 
Content Factory (2016). How Much Does Social Media Marketing Cost? N.d. Retrieved from: https://www. contentfac.com/how-much-does-social-media-marketing-cost/ (accessed 25 May 2018).

Creswell, J.W. (1998). Qualitative inquiry and research design: Choosing among five traditions. Thousand Oaks, CA: Sage Publications

Davis, C.H. (2013). Audience Value and Transmedia Products. In T. Storsul \& A.H. Krumsvik (Eds.), Media Innovations. A Multidisciplinary Study of Change (pp. 175-190). Stockholm: Nordicom

Desrochers, N., \& Apollon, D. (Eds.) (2014). Examining Paratextual Theory and its Applications in Digital Culture. Hershey, PA: IGI Global

Ellis, C., Adams, T.E., \& Bochner, A.P. (2011). Autoethnography: An overview, Forum Qualitative Sozialforschung / Forum: Qualitative Social Research, 12(1), Art. 10, http://nbn-resolving.de/urn:nbn:de:0114fqs1101108.

Feagin, J., Orum, A., \& Sjoberg, G. (1991). A case for the case study. Chapel Hill: University of North Carolina Press.

Feloni, R. (2013). The 10 Biggest Social Media Marketing Fails of 2013. Business Insider, 24 November. Retrieved 1 December from https://www.businessinsider.com/10-worst-social-media-marketing-fails-of2013-2013-11? $\mathrm{r}=\mathrm{US} \& \mathrm{IR}=\mathrm{T}$
Ferriter, M.M. (2009). 'Arguably the greatest': Sports fans and communities at work on Wikipedia. Sociology of Sport Journal, 26(1), 127-154.

Ford, S. (2017). WWE's Storyworld and the Immersive Potentials of Transmedia Storytelling. In W.L. Benjamin, D. Kurtz \& M. Bourdaa (Eds.), The Rise of Transtexts: Challenges and Opportunities (pp. 169-186). London: Routledge

Genette, G. (1997). Paratexts: Thresholds of Interpretation. Cambridge: Cambridge University Press.

Gray, J. (2010). Show Sold Separately. Promos, Spoilers, and Other Paratexts. New York: NYU Press.

Gronroos, C. (2004). The relationship marketing process: Communication, interaction, dialogue, value. Journal of Business and Industrial Marketing, 19(2), 99-113. Gruszka I, (2015). Genius Marketing - Volkswagen Rally The World. Medium. Retrieved from: https://medium. com/non-tech-girl-in-tech/genius-marketing-volkswagen-rally-the-world-d75977eb36c (accessed 22 May 2018).

Harrison, H., Birks, M., Franklin, R., \& Mills, J. (2017). Case Study Research: Foundations and Methodological Orientations. Forum Qualitative Sozialforschung / Forum: Qualitative Social Research, 18(1), Art. 19, http://nbn-resolving.de/urn:nbn:de:0114-fqs1701195.
Hartmann, T., Stuke, D., \& Daschmann, G. (2008). Positive parasocial relationships with drivers affect suspense in racing sport spectators. Journal of Media Psychology: Theories, Methods, and Applications, 20(1), 24-34.

Hassan, D., \& O’Connor, S. (2009). The Socio-Economic Impact of FIA World Rally Championship. Sport in Society, 12(6), 709-724.

Horton, D., \& Wohl, R. R. (1956). Mass communication and para-social interaction. Psychiatry, 19(3), 215229.

Hutchins, B., \& Rowe, D. (2012). Sport Beyond Television: The Internet, Digital Media, and the Rise of Networked Media Sport. New York: Routledge.

Jenkins, H. (2006). Convergence Culture. New York: New York University Press.

Jenkins, H. (2007). Transmedia story telling 101. Retrieved from http://henryjenkins.org/2007/03/transmedia_storytelling_101.html (accessed 10 June 2017).

Jenkins, H., Ford, S., \& Green, J. (2013). Spreadable media: creating value and meaning in a networked culture. New York: New York University Press.

Kassing, J. W., \& Sanderson, J. (2015). Playing in the new media game or riding the virtual bench: Confirming and disconfirming membership in the community of sport. Journal of Sport \& Social Issues, 39(1), 3-18. 
Kozinets, R. (2002). The Field Behind the Screen: Using Netnography for Marketing Research. Journal of Marketing Research, 39(1), 61-72.

Kunkel, T., Funk, D.C., \& Mueck, F. (2014). Sport fan engagement through gamification in a digital media environment. Paper presentation at the XII Sport Marketing Association conference. October 21-25, 2014

Kunz, R.E., Elsässer, F., \& Santomier, J. (2016). Sportrelated branded entertainment: the Red Bull phenomenon. Sport, Business and Management: An International Journal, 6(5), 520-541.

Köhler, U. (2014). Digitalising Live Rally Experiences. Avantgarde, February 4. Retrieved from https://www. avantgarde.net/digitalising-live-rally-experiences/ (accessed 22 May 2018).

Manning, J.E., \& Adams, T.E. (2015). Popular Culture Studies and Autoethnography: An Essay on Method. Popular Culture Studies Journal, 3(1-2), 187-222.

Manoli, A.E. (2018). Sport marketing's past, present and future; an introduction to the special issue on contemporary issues in sports marketing. Journal of Strategic Marketing, 26(1), 1-5, DOI: 10.1080/0965254X.2018.1389492

McClearen, J. (2017). 'We are all fighters': The transmedia marketing of difference in the Ultimate Fighting Championship (UFC). International Journal of Communication, 11, 3224-3241.
Meng, M.D, Stavros, C., \& Westberg, K. (2015). Engaging fans through social media: implications for team identification. Sport, Business and Management: An International Journal, 5(3), 199-217.

Merriam, S.B. (1998). Qualitative research and case study applications in education. San Francisco: Jossey-Bass Publishers.

Mittell, J. (2015). Complex TV: The Poetics of Contemporary Television Storytelling. New York: New York University Press.

Mullin, B. (1983). Sport marketing, promotion and public relations. Amherst, MA: National Sport Management.

Næss, H.E. (2014). A Sociology of the World Rally Championship. History, Identity, Memories and Place. Basingstoke: PalgraveMacmillan

Næss, H.E. (2016). Spectator experience management in the FIA World Rally Championship. Choregia: Sport International Management Journal, 12(2), 55-66.

O'Connor, S. (2005). The Marketing Strategy of the World Rally Championship. International Journal of Sports Marketing and Sponsorship, 6(4), 63-68.

Oates, T.P., \& Vogan, T. (2014). The Sporting Paratext, Reception, and the Male Domain in CBS's "One Shining Moment”. Communication and Sport, 2(4), 328-344.

Pegoraro, A. (2014). Twitter as Disruptive Innovation in Sport Communication. Communication \& Sport, 2(2), 132-137.
Phillips, A. (2012). A Creator's Guide to Transmedia Storytelling: How to Captivate and Engage Audiences Across Multiple Platforms. New York: McGraw-Hill.

Pronschinske, M., Groza, M.D., \& Walker, M. (2012). Attracting Facebook 'Fans': The Importance of Authenticity and Engagement as a Social Networking Strategy for Professional Sport Teams. Sport Marketing Quarterly, 21(4), 221-231.

Quinton, S., \& Harridge-March, S. (2010). Relationships in online communities: the potential for marketers. Journal of Research in Interactive Marketing, 4(1), 59-73.

Rasku, R., \& Ahonen, A. (Eds.) (2015). Sport Business Intelligence: Case WRC Rally Finland. Jyväskylä: JAMK University of Applied Sciences.

Robertson, R. (1995). Glocalization: Time-Space and Homogeneity-Heterogeneity. In M. Featherstone, S. Lash \& R. Robertson (Eds.) Global Modernities (pp. 25-44). London: Sage.

Rowe, D. (2011). Global media sport: Flows, forms and futures. New York, NY: Bloomsbury Academic.

Sanderson, J., \& Kassing, J.W. (2014). New media and the evolution of fan-athlete interaction. In A.C. Billings \& M. Hardin (Eds.) Routledge Handbook of Sport and New Media (pp. 247-259). London: Routledge. 
Sangalang, A., Johnson, J.M.Q., \& Ciancio, K.E. (2013). Exploring audience involvement with an interactive narrative: implications for incorporating transmedia storytelling into entertainment-education campaigns. Critical Arts, 27(1), 127-146

Santomier, J., \& Hogan, P. (2013). Social media and prosumerism: implications for sport marketing research In S. Söderman \& H. Dolles (Eds.) Handbook of Research on Sport and Business (pp. 179-201). Cheltenham, UK: Edward Elgar.

Scolari, C., \& Ilbrus, I. (2014). Transmedia Critical: Empirical Investigations into Multiplatform and Collaborative Storytelling. International Journal of Communication, 8, 2191-2200.

Sherwood, M., Nicholson, M., \& Marjoribanks, T. (2017). Controlling the Message and the Medium? The impact of sports organisations' digital and social channels on media access. Digital Journalism, 5(5), 513-531.

Shorty Awards (2017). 'RallytheWorld - Do it for the drive. About this entry'. Retrieved from http://shortyawards.com/8th/rally-the-world-do-it-for-the-drve-2 (accessed 27 June 2017).

Spinda, J. S., Earnheardt, A. C., \& Hugenberg, L. W. (2009). Checkered flags and mediated friendships: Parasocial interaction among NASCAR fans. Journal of Sports Media, 4(2), 31-55. doi:10.1353/jsm.0.0041
Stewart, B., Smith, C.T.A., \& Nicholson, M (2003). Sport Consumer Typologies: A Critical Review. Sport Marketing Quarterly, 12(4), 201-216.

Stake, R. E. (1995). The art of case study research. Thousand Oaks, CA: Sage.

Stauff, M. (2018). Non-Fiction Transmedia: Seriality and Forensics in Media Sport. M/C Journal, 21(1), Retrieved from http://journal.media-culture.org.au/ index.php/mcjournal/article/view/1372.

Strauss, A., \& Corbin, J. (1990). Basics of Qualitative Research. Thousand Oaks, CA: Sage.

Tussey, E. (2013). Desktop Day Games. Workspace Media, Multitasking and the Digital Baseball Fan. In Hutchins, B., \& Rowe, D. (Eds.), Digital Media Sport: Technology, Power and Culture in the Network Ssociety (pp. 37-51) New York: Routledge.

Williams, J., \& Chinn, S. J. (2010). Meeting relationshipmarketing goals through social media: a conceptual model for sport marketers. International Journal of Sport Communication, 3(4), 422-437. doi: 10.1123/ ijsc.3.4.422

WRC Fact book 2016 (2017). Retrieved from http://www. wrc.com/factbook/2016-2017/

Yin, R. (1994). Case study research: Design and methods (2nd ed.). Beverly Hills, CA: Sage Publishing.
Yoshida, M., Gordon, B., Heere, B., \& James, J.D. (2015). Fan community identification. An empirical examination of its outcomes in Japanese professional sport. Sport Marketing Quarterly, 24, 105-119. 